\title{
Aa. Vv., Dossier Jules Laforgue
}

\section{Ida Merello}

\section{(2) OpenEdition}

\section{Journals}

\section{Edizione digitale}

URL: http://journals.openedition.org/studifrancesi/27906

DOI: 10.4000/studifrancesi.27906

ISSN: 2427-5856

\section{Editore}

Rosenberg \& Sellier

\section{Edizione cartacea}

Data di pubblicazione: 31 décembre 2006

Paginazione: 630

ISSN: 0039-2944

\section{Notizia bibliografica digitale}

Ida Merello, «Aa. Vv., Dossier Jules Laforgue », Studi Francesi [Online], 150 (L | III) | 2006, online dal 30 novembre 2015, consultato il 08 novembre 2020. URL : http://journals.openedition.org/studifrancesi/ 27906 ; DOI : https://doi.org/10.4000/studifrancesi.27906

\section{Questo documento è stato generato automaticamente il 8 novembre 2020.}

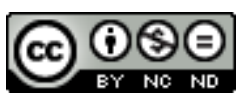

Studi Francesi è distribuita con Licenza Creative Commons Attribuzione - Non commerciale - Non opere derivate 4.0 Internazionale. 


\title{
Aa. Vv., Dossier Jules Laforgue
}

\author{
Ida Merello
}

\section{NOTIZIA}

Dossier Jules Laforgue, «Histoires littéraires», juill-août-sept 2005, n 23.

2005

1 Il dossier comprende un articolo di Jean-Louis DEBAUVE (Trois proses inédites de Laforgue, pp.7-12), uno di Henri SCEPI (Jules Laforgue: portrait de l'artiste en liquidateur de biens, pp. 13-25) la presentazione di Vingt poèmes inédits a opera di J-J.LEFRÈRE, M.DOTTIN-ORSINI, JL.DEBAUVE, pp. 27-58.

2 Debauve sceglie, dal voluminoso corpus dei brouillons che Laforgue ha lasciato, tre testi che possono a suo parere migliorare la conoscenza del pensiero giovanile dell'autore. Il primo si compone di riflessioni sulla felicità, con il progetto di costruzione di una cattedrale immaginaria, simboleggiante l'amore e la giustizia. Vi è inoltre un esplicito rinvio a una raccolta non portata a termine, Le Sanglot de la Terre (di cui tra l'altro inizialmente il titolo doveva riguardare una cattedrale) che rimane finora l'unica osservazione recuperata in proposito.

3 Il secondo testo presentato è dedicato al pittore lionese Paul-Joseph Chenavard (1807-1895), interessante perché nello stesso periodo di composizione (1880-1881) Laforgue stava preparando un romanzo dal titolo Un raté, in cui il protagonista è definito un "Chenavard discepolo di Schopenhauer". Il testo non si presenta però come una critica d'arte, sviluppandosi soprattutto a margine di osservazioni tratte dall'Art philosophique di Baudelaire.

4 L'ultimo testo è una descrizione del Reno, redatta durante il soggiorno a Coblenza (1885). Osservazioni simili compaiono già nel carnet del 1884-1885 e nei frammenti di novelle pubblicate nel tomo III delle Oeuvres complètes, ma il testo è particolarmente importante per i riferimenti all'imperatrice Augusta e alla sua corte. HENRI SCEPI, dopo aver ricordato come già i contemporanei tendessero a una semplificazione caricaturale del ritratto di Laforgue, mette in evidenza come tuttavia Fénéon e Viélé-Griffin siano 
stati i principali promotori della conoscenza delle sue opere a partire dal 1890 , individuando in lui il poeta dell'avvenire. L'A. mostra come Laforgue sia stato in effetti liquidatore del passato attraverso l'uso particolare di ironia e humour. L'ironia nasce dall'amalgama, sotto forma di citazioni o di allusioni, di frammenti di forme con pluralità di registri. Così le opere di Laforgue non sono la manifestazione di un soggetto parlante, ma puro ritmo, e la funzione poetica perde ogni funzione sacrale, mentre i valori assoluti sono attribuiti alla tecnica. J-J.LEFRÈre, M.DOTTIN-ORSINI, J-L.DEBAUVE presentano venti poesie inedite provenienti dal dossier di René Chauvelot, che riuscì a raccogliere numerosi testi grazie alla dispersione, negli anni Sessanta, di un fondo Laforgue e dall'apertura degli archivi del «Mercure de France». Le venti poesie qui pubblicate vanno a completare la ricostruzione del Sanglot de la Terre, confermando la sua grande unità compositiva. 